\title{
Spiromax, a New Dry Powder Inhaler: Dose Consistency under Simulated Real-World Conditions
}

\author{
Giorgio Walter Canonica, MD, ${ }^{1, \star}$ Jan Arp, MSc, \\ Johan René Keegstra, MSc, PharmD, ${ }^{3}$ and Henry Chrystyn, $\mathrm{PhD}^{4, *}$
}

\begin{abstract}
Background: Spiromax $^{\circledR}$ is a novel dry powder inhaler for patients with asthma or chronic obstructive pulmonary disease (COPD). The studies presented here provide further data on attributes (in vitro dosing consistency with budesonide-formoterol (DuoResp) Spiromax; flow rates through empty versions of the Spiromax and Turbuhaler inhaler) of importance to patients with asthma or COPD.

Methods: Dose-delivery studies were performed using low-, middle-, and high-strength DuoResp Spiromax. Dose consistency was assessed over inhaler life. Total emitted doses (TEDs) were measured at various flow rates, after exposure to high and low temperature or humidity, at different inhaler orientations, and after dropping the inhaler. The criterion for evaluating dose uniformity was whether mean TEDs were within the product specification limits. In separate studies, flow rates were measured after training, using the patient information leaflets, and again after enhanced training as part of a randomized, open-label, cross-over study. Results: Mean values for both budesonide and formoterol were within 85\%-115\% of the label claim for each strength of DuoResp Spiromax for initial dose uniformity and for the other investigated conditions (temperature, humidity, orientation, dropping, knocking), with the exception of approximately an $80 \%$ increase in first dose after dropping the inhaler (subsequent doses not affected). In the flow rate patient study, two patients' inhalations with Spiromax and six with Turbuhaler were $<30 \mathrm{~L} / \mathrm{min}$. The majority of asthma patients $[91 \%$ (Spiromax) versus $82 \%$ (Turbuhaler)] achieved the preferred flow rate of $>60 \mathrm{~L} / \mathrm{min}$.

Conclusions: DuoResp Spiromax consistently meets dose uniformity criteria, under controlled laboratory conditions and with variations intended to mimic real-world use. Following enhanced training, all patients in the flow study were able to achieve the minimal inspiratory flow rate of $>30 \mathrm{~L} / \mathrm{min}$, which is required for effective treatment.
\end{abstract}

Key words: asthma, COPD, dose consistency, flow rate, Spiromax

\section{Introduction}

THALERS ARE THE MAINSTAY DEVICES for daily treatment to control symptoms of asthma and chronic obstructive pulmonary disease (COPD). ${ }^{(1)}$ Poor technique is common with inhalers, and this has been linked to impaired control of symptoms. ${ }^{(2,3)}$ Healthcare professionals can help to address poor inhaler technique (and therefore improve adherence) by providing support to and educating their patients, ${ }^{(4)}$ but the device itself and its suitability for the patient are important considerations. To ensure that patients always receive an appropriate dose, inhalers should deliver a consistent dose of the drug or drug combination during normal use and in a variety of different environmental conditions, such as variations in temperature.

Dry powder inhalers (DPIs) are breath-actuated so there is no need for users to coordinate actuation with inhalation. Using a passive DPI device, however, requires a degree of inspiratory

\footnotetext{
${ }^{1}$ University of Genoa, Genoa, Italy. ${ }^{2}$ Teva Pharmachemie, Haarlem, The Netherlands. ${ }^{3}$ Formerly Teva Pharmachemie, Haarlem, The Netherlands. ${ }^{4}$ Inhalation Consultancy Ltd, Leeds, United Kingdom.

*Co-primary authors

(C) The Author(s) 2015; Published by Mary Ann Liebert, Inc. This Open Access article is distributed under the terms of the Creative Commons Attribution Noncommercial License (http://creativecommons.org/licenses/by-nc/4.0/) which permits any noncommercial use, distribution, and reproduction in any medium, provided the original author(s) and the source are credited.
} 
flow to deaggregate the formulation and obtain an accurate dose. ${ }^{(1,5,6)}$ To ensure sufficient deaggregation, a minimum inspiratory flow rate of $30 \mathrm{~L} / \mathrm{min}$ has been suggested for effective treatment, ${ }^{(7-9)}$ but higher rates of around $60 \mathrm{~L} / \mathrm{min}$ are preferable. ${ }^{(5-7,10-12)}$ Furthermore, dose preparation errors when using a DPI are common ${ }^{(13,14)}$ and very likely to result in no dose being available for inhalation. It is important, therefore, to have information about the effect of these errors with respect to the dose that would be inhaled if these occur.

A novel multi-dose DPI, Spiromax ${ }^{\circledR}$ (Teva Pharmaceutical Industries, Petach Tikva, Israel), has been designed with the aim of providing high-dose uniformity with maximum ease of use. The formulation of the inhaled corticosteroid (budesonide) and the long-acting $\beta_{2}$ agonist (formoterol), DuoResp ${ }^{\circledR}$ $160 / 4.5$ and 320/9 $\mu \mathrm{g}$ ) in Spiromax has been approved for use in the European Union (EU) as a treatment for asthma and COPD in patients $(\geq 18$ years old) requiring inhaled corticosteroid/long-acting $\beta_{2}$ agonist combination therapy. ${ }^{(15)}$

The Spiromax inhaler was designed to look and feel like a conventional metered-dose inhaler, but the internal configuration is very different (Fig. 1). Drug delivery is via the $\mathrm{X}$ $\mathrm{ACT}^{\circledR}$ system, which comprises active metering (an air pump transfers the drug from the drug reservoir to the dose cup (when the cap is opened) and cyclone separator technology (turbulent airflow) breaks up the dry powder blend and separates fine drug particles from larger lactose particles. It has a simple procedure for use ('open, breathe, close'), a lactose taste to signify that the medication has been delivered, and a dose counter enabling treatment to be monitored accurately.

Through a series of studies, we measured the consistency of dose delivery with DuoResp Spiromax and also flow rates through the inhaler during use by patients with asthma or COPD. We designed in vitro studies to approximate normal patient use, including variations in temperature, humidity, and orientation, as well as dropping and knocking the inhaler. These studies were performed in consultation with regulatory authorities such as the European Medicines Agency (EMA) ${ }^{(16)}$ to ensure clinical relevance and suitability for marketing authorization applications. ${ }^{(16)}$ The EMA Guideline on the requirements for clinical documentation for orally inhaled products specifies a maximum allowable in vitro difference of $\pm 15 \%$ for airflow resistance, delivered dose, and inhaled volume. ${ }^{(17)}$

\section{Materials and Methods}

\section{DuoResp Spiromax for in vitro dose delivery studies}

DuoResp Spiromax inhalers were provided by Teva Pharmaceuticals. At the time of the study, Spiromax was not available commercially. Since there have been no major changes to the manufacturing process, the DuoResp Spiromax inhalers studied included batches that had been used for clinical investigations and are representative of devices in community use.

\section{In vitro studies of dose delivery}

In all of the dose delivery studies described below, drug doses were collected in accordance with the compendial procedure, ${ }^{(18)}$ using dose uniformity sampling apparatus (Fig. 2) and analyzed (quantified) by validated high-performance liquid chromatography. The chromatographic separations were

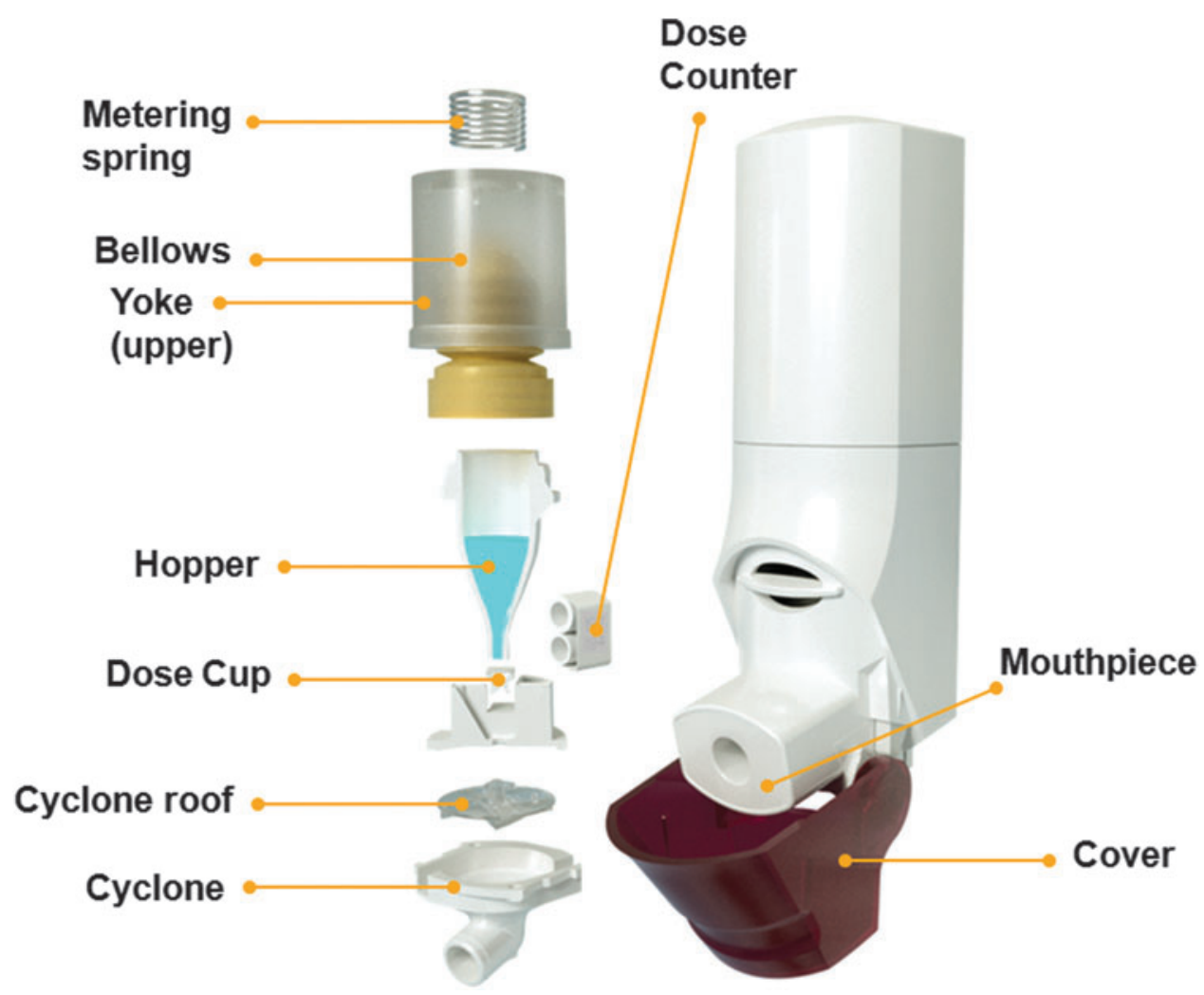

FIG. 1. Configuration of the Spiromax inhaler. 


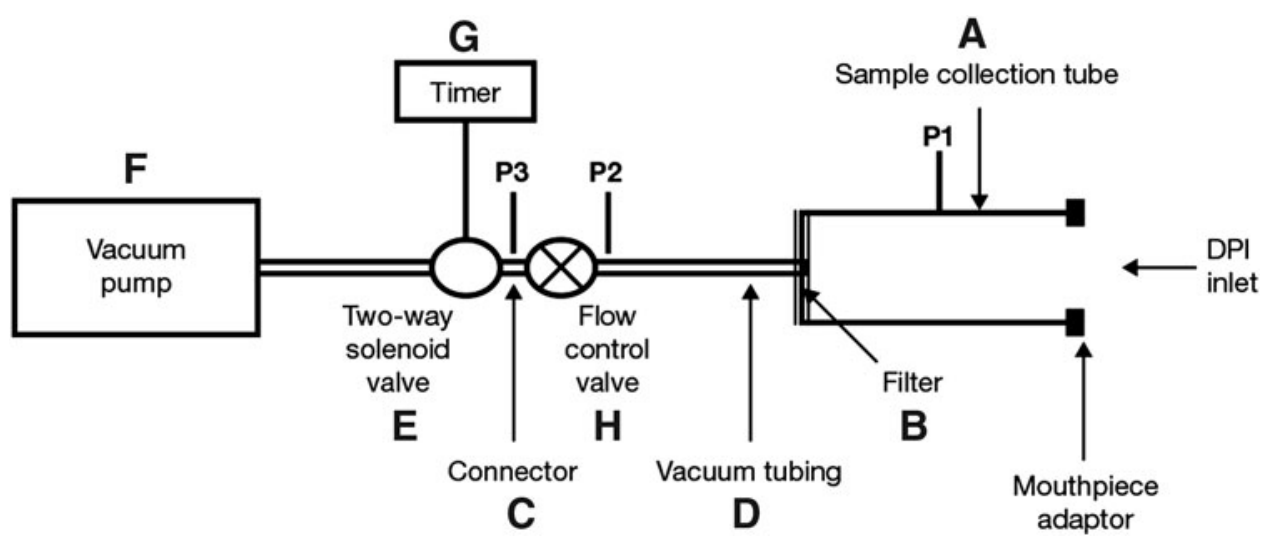

FIG. 2. Dosage Unit Sampling Apparatus (according to the European Pharmacopoeia).

carried out at $40^{\circ} \mathrm{C}$ column temperature on an XBridge $\mathrm{C} 18$, $3.5 \mu \mathrm{m}, 2.1 \times 20 \mathrm{~mm}$ IS analytical column (Waters, USA) using a sample volume of $40 \mathrm{~mL}$. The mobile phase was methanol: $10 \mathrm{mM}$ sodium dihydrogen phosphate monohydrate adjusted to $\mathrm{pH} 3.1$ with phosphoric acid (60:40 v/v) containing $12.5 \mathrm{mM}$ sodium dodecyl sulfate. The mobile phase was delivered at a flow of $0.4 \mathrm{~mL} / \mathrm{min}$ and the injection volume was $10 \mu \mathrm{L}$. UV detection at $245 \mathrm{~nm}(0-1.0 \mathrm{~min})$ and $214 \mathrm{~nm}$ (1.0 min to end of run time) was used.

The calibration curves were linear $\left(\mathrm{r}^{2}=1.000\right)$ over budesonide concentrations ranging from 0.1 to $50 \mu \mathrm{g} / \mathrm{mL}$ and formoterol fumarate dihydrate concentrations ranging from 4.5 to $1350 \mathrm{ng} \mathrm{mL}^{-1}(n=11$ levels $)$. The method had an accuracy of $99 \%-100 \%$ for budesonide over the full range and an accuracy of $98 \%-101 \%$ for formoterol in the

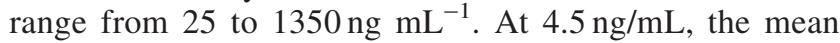
formoterol recovery was $112 \%$. For budesonide, the intermediate precision coefficient of variation (CV) was $1.3 \%, 1.1 \%$, and $<0.8 \%$, respectively, at three different concentrations $(1,6.25,50 \mu \mathrm{g} / \mathrm{mL})$. For formoterol, the intermediate precision $\mathrm{CV}$ was $4.3 \%, 0.7 \%$, and $0.9 \%$, respectively, at three different concentrations $(4.5,225$, $1350 \mathrm{ng} / \mathrm{mL})$.

The quantitation limit (QL) of budesonide was $2 \mathrm{ng} / \mathrm{mL}$ $(0.05 \%$ relative to the product label claim of the middle strength drug product, i.e., $160 \mu \mathrm{g}$ budesonide). The QL of formoterol was $2 \mathrm{ng} / \mathrm{mL}$ ( $2 \%$ relative to the product label claim of the middle-strength drug product, i.e., $4.5 \mu \mathrm{g}$ formoterol fumarate dihydrate).

Dose consistency over the inhaler lifetime. To measure uniformity of TEDs under standardized laboratory conditions, $4 \mathrm{~L}$ of air was drawn through the Spiromax inhaler at a rate of $62.5 \mathrm{~L} / \mathrm{min}$. Ten separate doses were measured for each inhaler: the first three doses from the beginning of inhaler life, middle four doses from the middle of inhaler life, and the last three doses from the end of inhaler life. Low-, middle-, and high-strength inhalers were investigated (80/4.5, 160/4.5, and $320 / 9 \mu \mathrm{g}$, respectively). Forty-one inhalers from three lowstrength batches, 42 from three middle-strength batches, and 42 from three high-strength batches resulted in a total of 125 DuoResp Spiromax inhalers being tested.

Table 1. Schemes Designed for Simulation of Real-World Dosing Conditions (Inhalers Carried by Analysts During Working-Day Hours)

\begin{tabular}{|c|c|c|c|c|c|}
\hline Scheme & $\begin{array}{l}\text { Inhaler } \\
\text { strength }\end{array}$ & Dosing regimen & $\begin{array}{l}\text { Duration } \\
\text { (days) }\end{array}$ & Number of inhalers & $\begin{array}{l}\text { Uniformity of dose } \\
\text { delivery assessments }\end{array}$ \\
\hline A & Low $^{\mathrm{a}}$ & One inhalation twice daily & 72 & 6 (three from each of the two batches) & 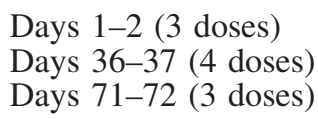 \\
\hline B & Low $^{\mathrm{a}}$ & Four inhalations twice daily & 21 & 6 (three from each of the two batches) & $\begin{array}{l}\text { Day } 1 \text { (3 doses }) \\
\text { Day } 10 \text { (4 doses) } \\
\text { Day } 21 \text { ( } 3 \text { doses })\end{array}$ \\
\hline $\mathrm{C}$ & Middle $^{b}$ & One inhalation twice daily & 90 & 9 (three from each of the two batches) & $\begin{array}{l}\text { Days } 1-2(3 \text { doses }) \\
\text { Days } 45-48 \text { ( } 4 \text { doses }) \\
\text { Days } 87-90(3 \text { doses })\end{array}$ \\
\hline $\mathrm{D}$ & $\operatorname{High}^{\mathrm{c}}$ & One inhalation twice daily & 32 & 6 (three from each of the two batches) & $\begin{array}{l}\text { Days } 1-4 \text { ( } 3 \text { doses }) \\
\text { Days } 15-18 \text { ( } 4 \text { doses }) \\
\text { Days } 29-32 \text { (3 doses) }\end{array}$ \\
\hline $\mathrm{E}$ & $\operatorname{High}^{\mathrm{c}}$ & Two inhalations twice daily & 16 & 6 (three from each of the two batches) & $\begin{array}{l}\text { Day } 1(3 \text { doses }) \\
\text { Day } 8 \text { ( } 4 \text { doses }) \\
\text { Days } 15-16(3 \text { doses })\end{array}$ \\
\hline
\end{tabular}

${ }^{\mathrm{a}} 80 / 4.5 \mu \mathrm{g}$ per dose; ${ }^{\mathrm{b}} 160 / 4.5 \mu \mathrm{g}$ per dose; ${ }^{\mathrm{c}} 320 / 9 \mu \mathrm{g}$ per dose. 
Doses delivered at different flow rates. TEDs were measured over a range of flow rates $(40,60$, and $90 \mathrm{~L} / \mathrm{min}$, set in accordance with the compendial procedure), ${ }^{(18)}$ under standardized laboratory conditions (i.e., above the minimum inspiratory flow rate of $30 \mathrm{~L} / \mathrm{min}$ suggested for deaggregation). For each flow rate, $4 \mathrm{~L}$ of air was drawn through the inhaler. Ten doses were measured for each inhaler, as described above. Low-, middle-, and high-strength DuoResp Spiromax inhalers were included, with a total of 27 inhalers tested (three inhalers from each of the three batches of each strength).

Doses delivered upon simulation of patient use. Inhalers were carried by analysts during working-day hours so that they would be subjected to a variety of knocks and vibrations, as well as everyday variations in temperature and humidity. Outside working-day hours, inhalers were stored upright at $22^{\circ} \mathrm{C}$ and $40 \%-60 \%$ relative humidity. Actuations were performed at frequencies designed to simulate realworld clinical dosing regimens (Table 1). A total of 33 DuoResp Spiromax inhalers were included in these experiments: 12 low strength, nine middle strength, and 12 high strength.

Doses delivered after exposure to high and low temperatures. Nine DuoResp Spiromax inhalers (three each of low, middle, and high strength) were subjected to three temperature cycles to mimic conditions during transport from factory to dispenser. Inhalers were stored wrapped in the original packaging. Each cycle comprised: 2 days of freezer storage $\left(-20^{\circ} \mathrm{C}\right), 2$ days of high-temperature storage $\left(40^{\circ} \mathrm{C}\right.$, using a temperature controlled cabinet), and 3 days of room-temperature storage $\left(22^{\circ} \mathrm{C}\right)$. Following completion

\section{A Budesonide}

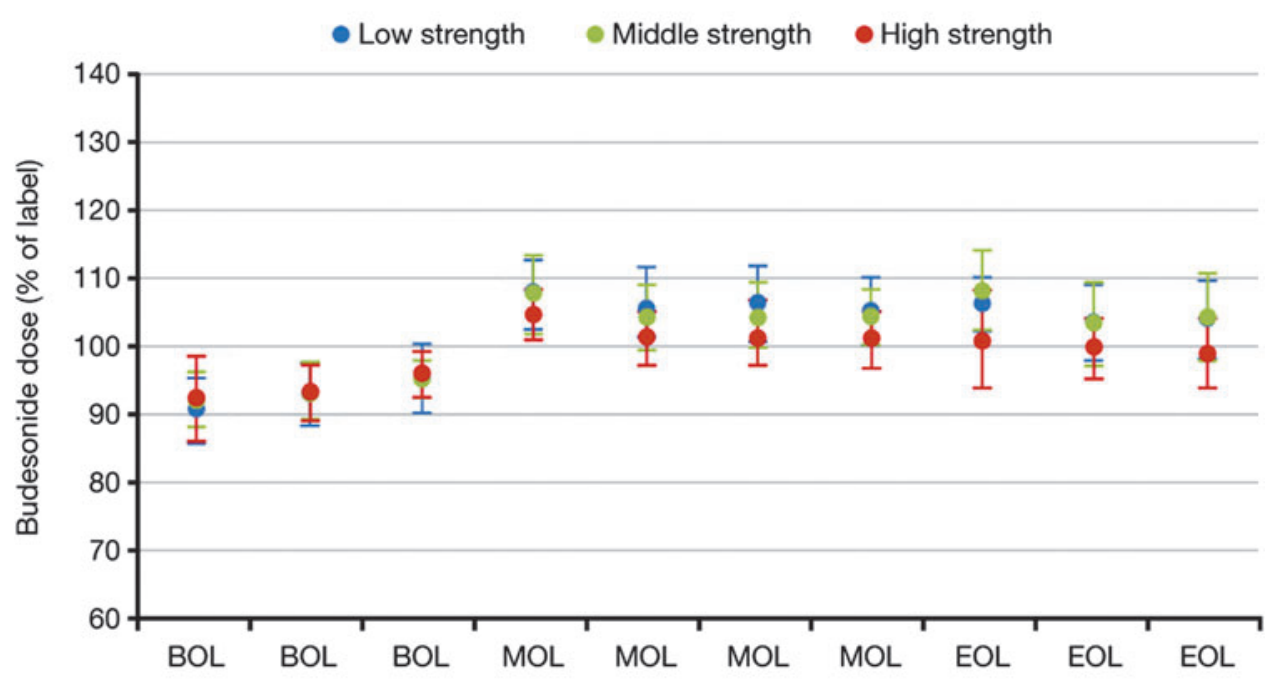

B Formoterol

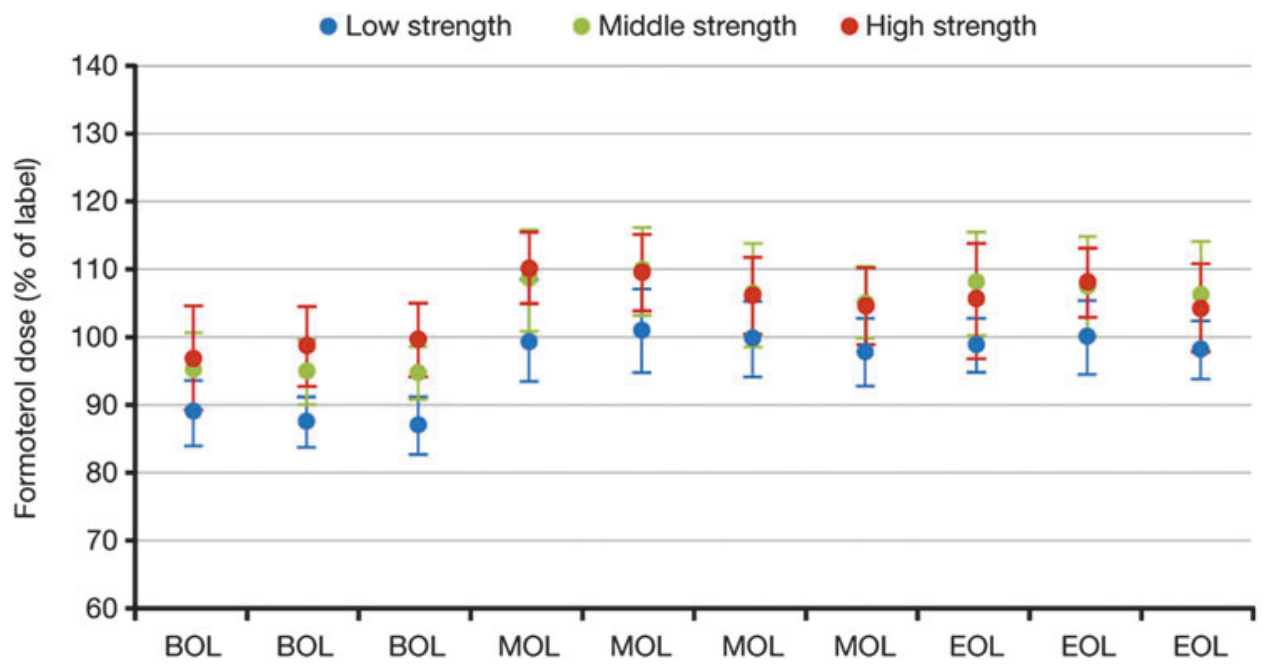

FIG. 3. Mean* (SD) total emitted doses of budesonide and formoterol at the beginning (BOL), middle (MOL), and end (EOL) of inhaler life, with low-, middle-, and highstrength DuoResp Spiromax. *Mean of three batches. Low strength: 80/4.5 $\mu \mathrm{g}$ per dose; middle strength: $160 / 4.5 \mu \mathrm{g}$ per dose; high strength: $320 / 9 \mu \mathrm{g}$ per dose. BOL, beginning of life; EOL, end of life; MOL, middle of life; SD, standard deviation. 
of the three cycles, dose delivery was measured over ten doses (three at the beginning of inhaler life, four at middle of inhaler life, and three at end of inhaler life) at standard laboratory conditions. Mean values were calculated for the 10 actuations.

Doses delivered after exposure to high or low humidity. TEDs were measured at three different relative humidities (low: 25\%-31\% ; reference: $46 \%-54 \%$; and high: $72 \%-79 \%$, using a ClimateZone temperature and humidity controlled work space cabinet [a1-envirosciences $\mathrm{GbH}$, Düsseldorf]) to mimic conditions encountered during patient use. Temperatures for the three humidity levels were $20^{\circ}-21^{\circ} \mathrm{C}$, $22^{\circ} \mathrm{C}$, and $23^{\circ}-27^{\circ} \mathrm{C}$, respectively. Inhalers (unwrapped, mouthpiece closed) were stored at each humidity level for at least 14 hours before being tested. Testing was performed in the ClimateZone cabinet. Dose delivery was measured over 10 doses (three at the beginning of inhaler life, four at middle of inhaler life, and three at end of inhaler life). Low-, middle-, and high-strength DuoResp Spiromax inhalers were included, with a total of 27 inhalers tested (three inhalers from each of the three batches of each strength).

Doses delivered at different inhaler orientations. TEDs were measured with inhalers held at three different orientations $\left(+45^{\circ},-45^{\circ}\right.$, and upright), in an initial study under standardized laboratory conditions. The impact of orientation was assessed separately for actuation and inhalation. Dose delivery was measured over 10 doses (three at the beginning of inhaler life, four at middle of inhaler life, and three at end of inhaler life). Low- and high-strength DuoResp Spiromax inhalers were included with a total of 90 inhalers tested (three inhalers from each of the three batches (of each strength) tested at each orientation, for both actuation and inhalation).

A follow-up study was performed to assess the impact of orientation at $+90^{\circ},-90^{\circ}$, and upright, for actuation and inhalation. This study included only one batch of high-

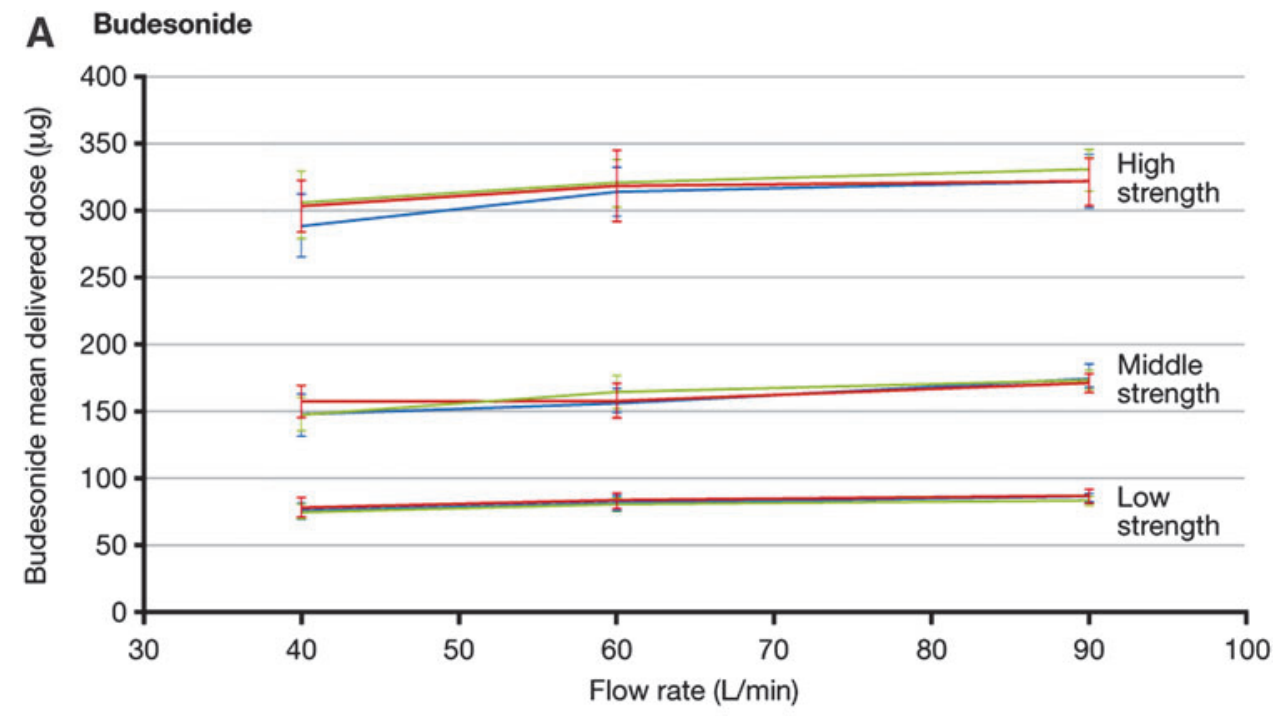

B Formoterol

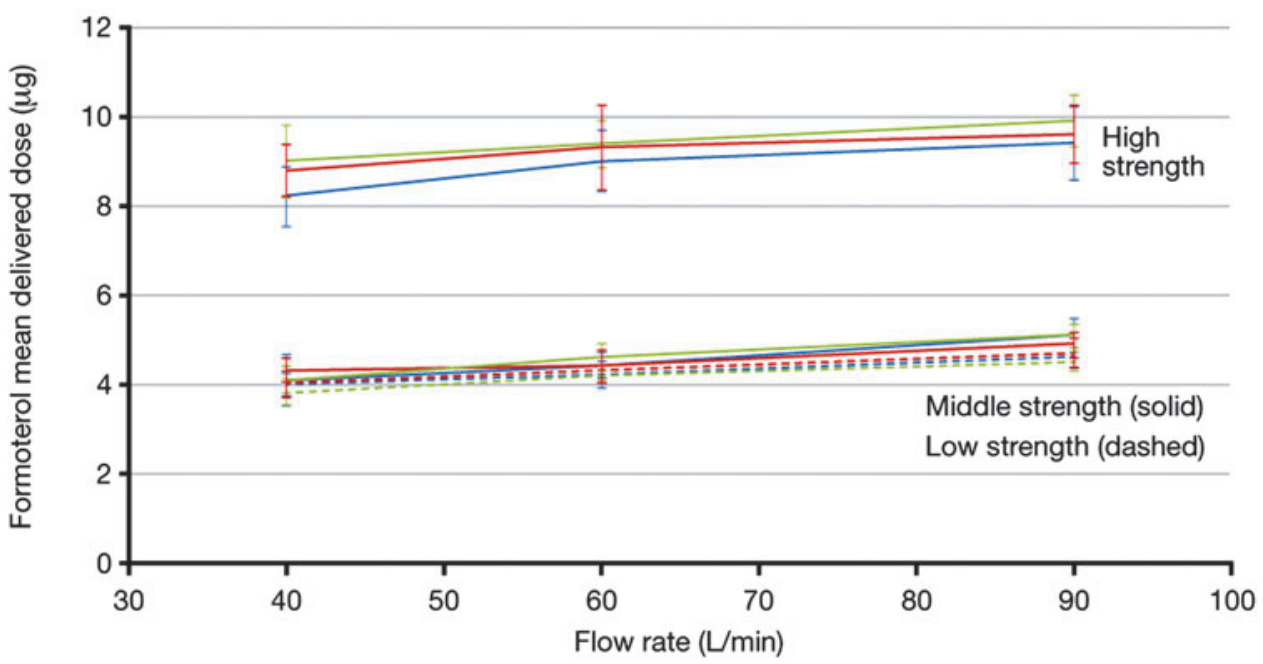

FIG. 4. Effects of flow rate on emitted dose of budesonide and formoterol delivered by low-, middle-, and high-strength DuoResp Spiromax. Low strength: 80/4.5 $\mu$ g per dose; middle strength: 160/4.5 $\mu \mathrm{g}$ per dose; high strength: $320 / 9 \mu \mathrm{g}$ per dose. Colored lines represent results from different batches. 
strength DuoResp Spiromax inhalers, with 15 inhalers tested, but otherwise the methods reflected those used for the initial study.

Doses delivered after dropping the inhaler. Inhalers were dropped from a height of $90-110 \mathrm{~cm}$ onto a hard surface. Low-, middle-, and high-strength DuoResp Spiromax inhalers were included. Each test contained nine inhalers, three of each strength of DuoResp Spiromax. For the lowstrength product, one inhaler batch was tested, for the middle- and high-strength products, four inhaler batches were tested per strength (batches 1-4). The impact on the TED of dropping (all three strengths) the DuoResp Spiromax was assessed (batch 1). Inhalers from batch 1 were dropped three times (once at beginning of inhaler life, once at middle of inhaler life, and once at end of inhaler life).

Each inhaler in batch 1 was dropped with a different release orientation each time (vertical, upright; vertical, inverted; or horizontal, mouthpiece uppermost) and then the TED assessed. Dose delivery was measured over ten doses (three at the beginning of inhaler life, four at middle of inhaler life, and three at end of inhaler life). After the batch 1 tests, medium- and high-strength inhalers (batches 2-4) were tested for possible dosing build up after a single drop near the end of inhaler life (five doses were measured before dropping and five after dropping).

\section{Statistical analysis}

Regression analysis was used for the statistical analysis of the dose-amount recovered at different flow rates. An ANCOVA model was used for the statistical analysis of doses delivered upon simulation of patient use. A one-way ANOVA model was used for the statistical analyses of doses delivered with humidity conditions and different orientations.

\section{Overview of patient flow study}

Empty Spiromax and empty Symbicort ${ }^{\circledR}$ versions of the Turbuhaler (AstraZeneca) inhalers were used in the study and were provided as unused placebos by the manufacturers. The internal resistance (measured per the technique of Clark and Hollingworth, 1993) ${ }^{(19)}$ of the empty Spiromax inhaler was $0.100\left(\mathrm{cmH}_{2} \mathrm{O}\right)^{1 / 2}(\mathrm{~L} / \mathrm{min})^{-1}$ [equivalent to $0.0313 \mathrm{kPa}$ (kilopascal $\left.)^{1 / 2}(\mathrm{~L} / \mathrm{min})^{-1}\right]$, which is similar to the resistance of the commercially available Spiromax inhaler. The internal resistance of the Turbuhaler inhaler used was $0.107\left(\mathrm{cmH}_{2} 0\right)^{1 / 2}$ $(\mathrm{L} / \mathrm{min})^{-1}$ [equivalent to $0.0355 \mathrm{kPa}^{1 / 2}(\mathrm{~L} / \mathrm{min})^{-1}$ ], similar to commercially available Symbicort Turbuhaler. ${ }^{(9,20)}$

Inhalation characteristics were determined from singlevisit, randomized, open-label, cross-over studies when subjects inhaled using empty Spiromax and Turbuhaler inhalers. ${ }^{(21)}$ Inhalations were performed by children with asthma (6-11 years; $n=23)$, adolescents with asthma $(12-17$ years; $n=27)$, adults with asthma $(18-45$ years; $n=50)$, adults with COPD ( $>50$ years; $n=50)$, and healthy adult volunteers $(18-45$ years; $n=50)$.

Each DPI was attached to an inhalation profile recorder to measure the pressure changes during each inhalation maneuver. The pressure changes were monitored by a probe inserted into the inhalation channel of the inhaler. Pressure changes with time were downloaded to an Excel spreadsheet (Microsoft Corporation, Redmond, Washington, US) and converted to inhalation flow values according to the method described by Clark and Hollingworth ${ }^{(19)}$

From each profile, the peak inhalation flow (PIF in $\mathrm{L} / \mathrm{min}$ ) was obtained together with the maximum pressure change, inhalation volume, time of inhalation, time to reach the PIF, and the acceleration rate. ${ }^{(21)}$ Inhalation profiles were measured after verbal training using the patient information leaflet (PIL). After these inhalations through the two devices, the patients received enhanced training to achieve faster inhalations using the In-Check Dial (enhanced training). The inhalation profiles were then re-measured as they repeated the inhalations.

\section{Results}

\section{In vitro studies of dose delivery}

Dose uniformity over the inhaler lifetime. Dose uniformity data are shown in Figure 3. Mean values for all budesonide and formoterol doses (beginning, middle, and end of inhaler life) were within dose uniformity criteria. There was a general tendency for doses of budesonide and formoterol to be slightly lower at beginning of inhaler life than middle or end of inhaler life $(p<0.0001)$. However, there was no apparent dose build-up over the life of the inhaler. Uniformity of delivered dose met the compendial dose uniformity requirements for inhalation powders (not more than three of the 30 test values lie outside the limits of $75 \%-125 \%$ and no value lies outside the limits of $65 \%-135 \%$ of the average value) for all three strengths of DuoResp Spiromax.

Table 2. Effects of Flow Rate on Total Emitted Doses of Budesonide and Formoterol DeliVered By Low-, Middle-, AND High-Strength SpIromax

\begin{tabular}{lcccr}
\hline & & \multicolumn{3}{c}{ Budesonide } \\
\cline { 3 - 5 } Batch & $\begin{array}{l}\text { Flow rate } \\
\text { Lumber }\end{array}$ & Low & Middle $^{\mathrm{a}}$ & High $^{\mathrm{c}}$ \\
\hline 1 & 40 & $95(7)$ & $92(11)$ & $90(8)$ \\
1 & 60 & $102(7)$ & $97(7)$ & $98(6)$ \\
1 & 90 & $108(4)$ & $110(6)$ & $101(6)$ \\
2 & 40 & $98(10)$ & $99(8)$ & $95(7)$ \\
2 & 60 & $105(7)$ & $99(8)$ & $100(8)$ \\
2 & 90 & $109(6)$ & $107(4)$ & $101(6)$ \\
3 & 40 & $94(7)$ & $93(10)$ & $95(8)$ \\
3 & 60 & $100(6)$ & $103(7)$ & $100(6)$ \\
3 & 90 & $105(4)$ & $108(5)$ & $103(5)$ \\
\hline & & & Formoterol \\
Batch & Flow rate & & \\
number & $($ L/min) & Low ${ }^{\mathrm{a}}$ & Middle & High \\
\hline 1 & 40 & $89(7)$ & $91(14)$ & $91(8)$ \\
1 & 60 & $93(7)$ & $98(8)$ & $100(8)$ \\
1 & 90 & $102(5)$ & $113(8)$ & $104(9)$ \\
2 & 40 & $89(8)$ & $96(8)$ & $98(7)$ \\
2 & 60 & $96(7)$ & $98(8)$ & $103(10)$ \\
2 & 90 & $104(7)$ & $109(6)$ & $107(7)$ \\
3 & 40 & $84(7)$ & $91(12)$ & $100(9)$ \\
3 & 60 & $93(6)$ & $102(10)$ & $104(6)$ \\
3 & 90 & $100(5)$ & $113(7)$ & $110(6)$ \\
\hline & & & &
\end{tabular}

Values are mean percent relative to label claim and relative standard deviation (\%).

${ }^{\mathrm{a}} 80 / 4.5 \mu \mathrm{g}$ per dose; ${ }^{\mathrm{b}} 160 / 4.5 \mu \mathrm{g}$ per dose; ${ }^{\mathrm{c}} 320 / 9 \mu \mathrm{g}$ per dose. 
Doses delivered at different flow rates. In general, TED tended to increase with flow rate $(p<0.0001$ for all strengths and for both molecules; Fig. 4). However, the extent of change was limited, so that all doses were within $15 \%$ of the labelled quantity (Table 2). The results of this study were essentially the same for all three strengths of DuoResp Spiromax.

Doses delivered upon simulation of patient use. Although there was statistical significant increase $(p<0.0001)$ in TED from the first dose to the last dose, this increase was relatively small $(0.03 \%-0.13 \%$ [of label claim] for budesonide and formoterol across the dose ranges), TEDs were considered to be consistent from the first dose to the last dose during simulated in-use conditions (Fig. 5). This was true for all of the dosing schemes investigated, with durations up to 90 days. Results obtained during the simulations of pa- tient use were similar to those observed under standardized laboratory conditions, where results over the inhaler life were obtained during a single day.

Doses delivered after exposure to high and low temperatures. Exposure to extreme temperatures was found not to affect delivered doses (Table 3). Mean values for budesonide and formoterol were within $15 \%$ of the labeled quantity for all three strengths of DuoResp Spiromax. No single dose was outside the range $(75 \%-125 \%)$ of the delivered dose.

Doses delivered after exposure to high or low humidity. TED appeared to be unaffected by high or low humidity ( $p>0.05$, except for formoterol middle $[p<0.0001]$ and high strength $[p=0.0170]$; Table 3). Across the entire range of humidities tested, the largest dose variation was approximately $7 \%$

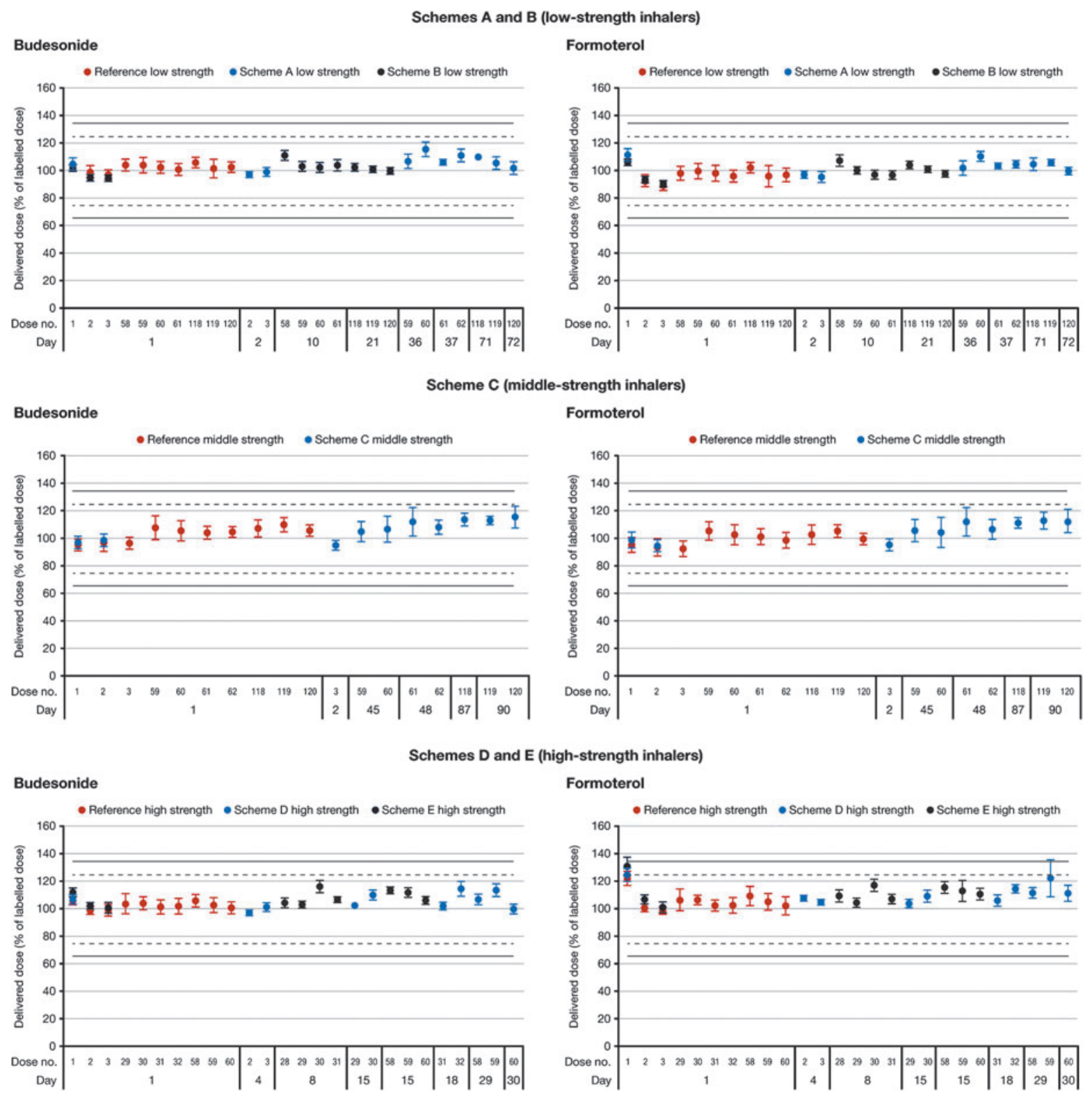

FIG. 5. Delivered doses during simulation of patient use with DuoResp Spiromax (simulation schemes shown in Table 1). Low strength: 80/4.5 $\mu$ g per dose; middle strength: $160 / 4.5 \mu$ g per dose; high strength: $320 / 9 \mu \mathrm{g}$ per dose. 
Table 3. Effects of Humidity and Temperature Cycling on Doses of Budesonide and Formoterol Delivered by Low-, Middle-, and High-Strength Spiromax

\begin{tabular}{|c|c|c|c|c|c|c|c|}
\hline \multirow[b]{2}{*}{ Batch } & \multirow[b]{2}{*}{ Test Condition ${ }^{\mathrm{a}}$} & \multicolumn{3}{|c|}{ Budesonide } & \multicolumn{3}{|c|}{ Formoterol } \\
\hline & & Low $^{\mathrm{b}}$ & Middle $e^{\mathrm{c}}$ & $\operatorname{High}^{\mathrm{d}}$ & $L_{o w} w^{\mathrm{b}}$ & Middle $^{\mathrm{c}}$ & $\operatorname{High}^{\mathrm{d}}$ \\
\hline \multicolumn{8}{|c|}{ Dose tested at extreme humidity levels (stored unwrapped, tested at humidity) } \\
\hline \multirow[t]{3}{*}{1} & Low & $98(8)$ & $103(7)$ & $102(4)$ & $93(9)$ & $104(6)$ & $106(7)$ \\
\hline & Standard & $104(5)$ & $99(6)$ & $99(5)$ & $98(7)$ & $96(6)$ & $104(7)$ \\
\hline & High & $101(4)$ & $104(7)$ & $101(7)$ & $96(6)$ & 104 (6) & 109 (9) \\
\hline \multirow[t]{3}{*}{2} & Low & $100(5)$ & $105(8)$ & 107 (6) & $96(6)$ & $104(7)$ & 109 (9) \\
\hline & Standard & 102 (4) & $106(6)$ & 104 (4) & $98(5)$ & 104 (6) & 108 (7) \\
\hline & High & $101(5)$ & $105(7)$ & 105 (6) & $96(6)$ & $104(8)$ & 108 (10) \\
\hline \multirow[t]{3}{*}{3} & Low & $103(7)$ & 105 (6) & 101 (7) & $96(7)$ & $102(5)$ & 107 (9) \\
\hline & Standard & $101(6)$ & $105(7)$ & $103(6)$ & $96(8)$ & $100(7)$ & 107 (10) \\
\hline & High & $101(4)$ & 105 (6) & 104 (6) & $98(5)$ & $107(7)$ & $111(9)$ \\
\hline \multicolumn{8}{|c|}{ Dose after temperature cycling (stored wrapped, tested at standard laboratory conditions) } \\
\hline 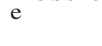 & Standard & $102(5)$ & $105(5)$ & $97(4)$ & $96(5)$ & $104(5)$ & $100(4)$ \\
\hline \multicolumn{8}{|c|}{ Reference } \\
\hline & Standard & $102(7)$ & $100(6)$ & $95(5)$ & $96(5)$ & $104(7)$ & $99(6)$ \\
\hline e & Standard & $102(7)$ & $100(4)$ & $96(5)$ & $96(6)$ & $98(5)$ & 99 (5) \\
\hline
\end{tabular}

${ }^{\mathrm{a}}$ Test condition Low: $20^{\circ}-21^{\circ} \mathrm{C}, 25 \%-31 \% \mathrm{RH}$; Standard: $21^{\circ}-23^{\circ} \mathrm{C}, 46 \%-54 \% \mathrm{RH}$; High: $23^{\circ}-27^{\circ} \mathrm{C}, 72 \%-79 \% \mathrm{RH}$; ${ }^{\mathrm{b}} 80 / 4.5 \mu \mathrm{g}$ per dose; ${ }^{\mathrm{c}} 160 / 4.5 \mu \mathrm{g}$ per dose; ${ }^{\mathrm{d}} 320 / 9 \mu \mathrm{g}$ per dose; ${ }^{\mathrm{e}}$ Low strength: Batch 2 (stored 3-6 months at $25^{\circ} \pm 2{ }^{\circ} \mathrm{C}, 60 \% \pm 5 \%$ RH); Middle strength: Batch 3; High strength: Batch 1 (both stored $9-12$ months at $25^{\circ} \pm 2^{\circ} \mathrm{C}, 60 \% \pm 5 \% \mathrm{RH}$ ). Values are mean percent relative to the label claim and relative standard deviation $(\%)$.

$\mathrm{RH}$, relative humidity.

(budesonide, high strength). There was no indication of dose increasing or decreasing with increasing humidity. All individual inhalers met product specifications for uniformity of dose delivery.

Doses delivered at different inhaler orientations. In the initial study, with orientations at $+45^{\circ}$ or $-45^{\circ}$ for either actuation or inhalation, there was no meaningful change in the dose of either budesonide or formoterol (no significant change [ $p>0.05]$, except for high strength budesonide, where the $+45^{\circ}$ actuation gave a significant but low change compared with control and $-45^{\circ}$ inhalation; Table 4). For example, the lowstrength dose of budesonide was $81.9 \mu \mathrm{g}$ with the inhaler held upright, $81.5 \mu \mathrm{g}$ and $82.9 \mu \mathrm{g}$ with actuation at $+45^{\circ}$ and $-45^{\circ}$, and $81.9 \mu \mathrm{g}$ and $81.2 \mu \mathrm{g}$ with inhalation at $+45^{\circ}$ and $-45^{\circ}$. Greater consistency was seen with formoterol and results were similar for both strengths of DuoResp Spiromax.

Although statistical differences observed based on orientation (the $-90^{\circ}$ [metering and inhalation] were higher than the control and $+90^{\circ}$ for budesonide $[p<0.0001]$ and formoterol $[p=0.0044])$, the dosing consistency was deemed to be maintained (Table 4, Fig. 6). The greatest deviation from the upright (control) dose was approximately $7 \%$ [budesonide, actuation at $-90^{\circ}$ : mean dose $324.4 \mu \mathrm{g}$ (Relative Standard Deviation [RSD] 4.0\%) compared with $303.8 \mu \mathrm{g}$ (RSD 4.9\%) in the upright position].

Doses delivered after dropping the inhaler. With one exception (broken mouthpiece cover after the third drop), all inhalers remained fully functional after being dropped. There was no powder leakage, no changes to dose counters, and no evidence that internal components had been damaged. At the middle or end of inhaler life, the first dose after dropping was increased by up to approximately $80 \%$ (both drugs; percentage increase lowest with high-strength DuoResp Spiromax) (Fig. 7). However, subsequent doses were not affected.

\section{Inhalation characteristics for asthma patients, COPD patients, and healthy volunteers}

Principal outcomes from this study are reported in detail elsewhere. ${ }^{(21)}$ Table 5 provides peak inspiratory flow rate (PIFR) by age and PIFR subgroups in patients with asthma or COPD. Considering both inhalers together, PIFR was $<30 \mathrm{~L} /$ min after standard PIL training in a minority of adult patients with asthma ( $n=2$; Spiromax: 1; Turbuhaler: 1$)$ or COPD ( $n=7$; Spiromax: 1; Turbuhaler: 5; same patient with both

Table 4. EfFects of Different Orientations ON DOSES OF BudESONIDE AND FORMOTEROL DELIVERED BY SPIROMAX

\begin{tabular}{|c|c|c|c|c|}
\hline \multirow[b]{2}{*}{ Orientation ('tilt') } & \multicolumn{2}{|c|}{ Budesonide } & \multicolumn{2}{|c|}{ Formoterol } \\
\hline & $L o w^{\mathrm{a}}$ & $H i g h^{\mathrm{b}}$ & $L_{o w}{ }^{\mathrm{a}}$ & $H i g h^{\mathrm{b}}$ \\
\hline \multicolumn{5}{|l|}{$45^{\circ}$ orientation study } \\
\hline $\begin{array}{l}\text { Control (upright } \\
\text { inhalation and } \\
\text { actuation) }\end{array}$ & $102(5)$ & $102(5)$ & $97(7)$ & $106(8)$ \\
\hline$+45^{\circ}$ (inhalation) & $102(6)$ & $104(5)$ & $96(6)$ & $106(8)$ \\
\hline$+45^{\circ}$ (actuation) & $102(7)$ & $103(5)$ & $96(7)$ & $106(9)$ \\
\hline$-45^{\circ}$ (inhalation) & $102(6)$ & $101(8)$ & $97(6)$ & $106(11)$ \\
\hline$-45^{\circ}$ (actuation) & $104(6)$ & $103(6)$ & $98(6)$ & $106(8)$ \\
\hline \multicolumn{5}{|l|}{$90^{\circ}$ orientation study } \\
\hline $\begin{array}{l}\text { Control (upright } \\
\text { inhalation and } \\
\text { actuation) }\end{array}$ & & $95(5)$ & & $98(7)$ \\
\hline$+90^{\circ}$ (inhalation) & & $97(4)$ & & $97(5)$ \\
\hline$+90^{\circ}$ (actuation) & & $98(5)$ & & $96(5)$ \\
\hline$-90^{\circ}$ (inhalation) & & $99(5)$ & & $100(5)$ \\
\hline$-90^{\circ}$ (actuation) & & $101(4)$ & & $99(4)$ \\
\hline
\end{tabular}

Values are mean percent relative to the label claim and relative standard deviation $(\%)$.

${ }^{\mathrm{a}} 80 / 4.5 \mu \mathrm{g}$ per dose; ${ }^{\mathrm{b}} 320 / 9 \mu \mathrm{g}$ per dose. 

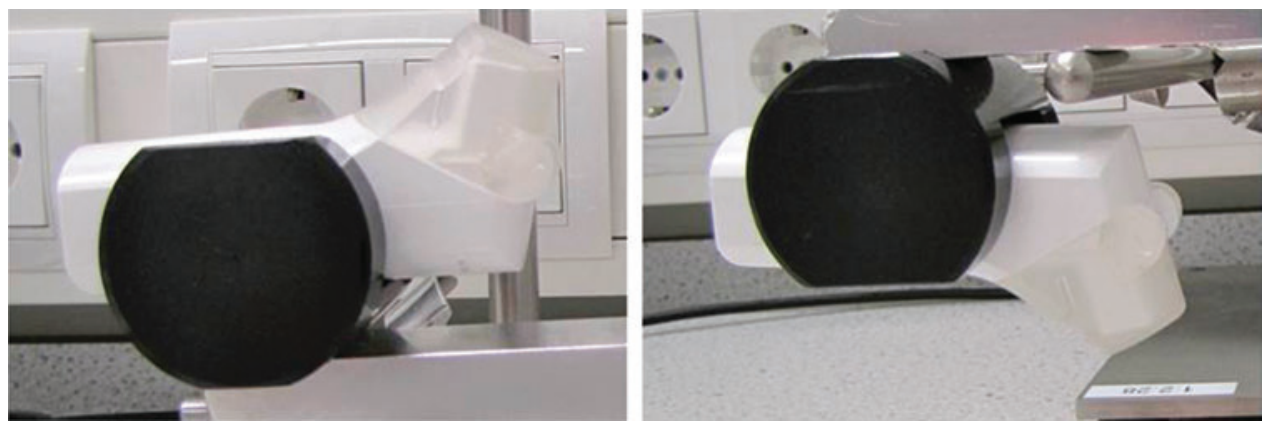

FIG. 6. Setup of Spiromax at an orientation of + or $-90^{\circ}$ for use in dose consistency analyses.

Spiromax and Turbuhaler: 1). This small number of patients is probably not clinically relevant and falls within expected numbers for DPIs. ${ }^{(9)}$

Following enhanced training, improvements in PIFR were observed with both inhalers and all patients achieved a PIFR $>30 \mathrm{~L} / \mathrm{min}$. With the Spiromax inhaler, $90 \%$ of patients in all three asthma groups achieved PIFRs exceeding $50 \mathrm{~L} / \mathrm{min}$ and $58 \mathrm{~L} / \mathrm{min}$ after standard PIL training and enhanced training, respectively. In adult COPD patients, $90 \%$ of patients achieved PIFRs of more than $33 \mathrm{~L} / \mathrm{min}$ with Spiromax after standard PIL training, increasing to $44 \mathrm{~L} / \mathrm{min}$ after enhanced training. Overall, PIFR values with Spiromax were higher than with Turbuhaler, after both standard PIL training and enhanced training. For example, more adult patients on the Turbuhaler $(n=7)$ did not achieve PIFR $>30 \mathrm{~L} / \mathrm{min}$ after standard PIL training compared with Spiromax $(n=3)$.

\section{Discussion}

The in vitro studies reported here show that DuoResp Spiromax delivers a highly consistent dose, under controlled laboratory conditions and with variations likely to reflect
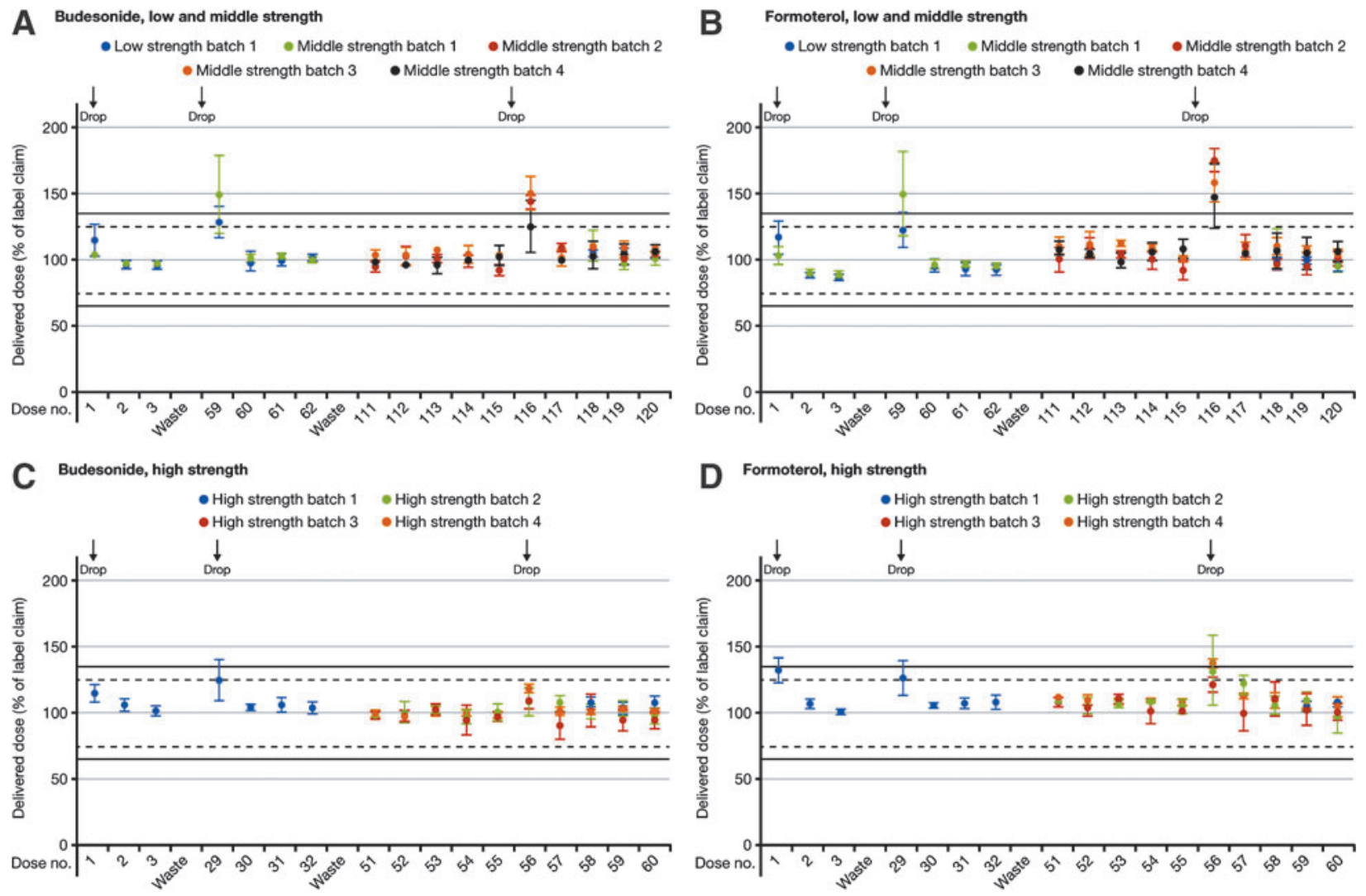

FIG. 7. Delivered doses of budesonide and formoterol after dropping the Spiromax inhaler at the beginning (first use), middle (median between first and last use), and end of inhaler life (last use) [ $\times 3$ drops; low-, middle-, and highstrength BF Spiromax (batch 1)] and towards the end of inhaler life [ $\times 1$ drop; middle-, and high-strength DuoResp Spiromax (batches 2-4)]. Low strength: 80/4.5 $\mu \mathrm{g}$ per dose; middle strength: 160/4.5 $\mu \mathrm{g}$ per dose; high strength: $320 /$ $9 \mu \mathrm{g}$ per dose. 
Table 5. Clinically Relevant Peak Inspiratory Flow Rate Subgroups per Device by Age Group

\begin{tabular}{|c|c|c|c|c|c|c|}
\hline \multirow[b]{2}{*}{ PIFR, L/min } & \multicolumn{3}{|c|}{ PIFR Turbuhaler, $\mathrm{n}(\%)$} & \multicolumn{3}{|c|}{ PIFR Spiromax, $\mathrm{n}(\%)$} \\
\hline & $<30$ & $30-59$ & $\geq 60$ & $<30$ & $30-59$ & $\geq 60$ \\
\hline \multicolumn{7}{|l|}{ Children (age 6-11) } \\
\hline PIL-training & $0(0)$ & $13(57)$ & $10(43)$ & $0(0)$ & $7(30)$ & $16(70$ \\
\hline Enhanced-training & $0(0)$ & $7(30)$ & $16(60)$ & $0(0)$ & $4(17)$ & $19(83$ \\
\hline \multicolumn{7}{|c|}{ Adolescence (age 12-17) } \\
\hline PIL-training & $0(0)$ & $14(52)$ & $13(48)$ & $0(0)$ & $11(41)$ & $16(59$ \\
\hline Enhanced-training & $0(0)$ & $4(15)$ & $23(85)$ & $0(0)$ & $1(4)$ & $26(96$ \\
\hline \multicolumn{7}{|l|}{ Adults (age 18-45) } \\
\hline PIL-training & $1(2)$ & $16(32)$ & $33(66)$ & $1(2)$ & $11(22)$ & $38(76$ \\
\hline Enhanced-training & $0(0)$ & 7 (14) & $43(86)$ & $0(0)$ & $3(6)$ & $47(94$ \\
\hline \multicolumn{7}{|l|}{ COPD (age $>50)$} \\
\hline PIL-training & $6(12)$ & $29(58)$ & $15(30)$ & $2(4)$ & $27(54)$ & $21(42$ \\
\hline Enhanced-training & $0(0)$ & $25(50)$ & $25(50)$ & $0(0)$ & $16(32)$ & $34(68$ \\
\hline
\end{tabular}

COPD, chronic obstructive pulmonary disease; PIFR, peak inspiratory flow rate; PIL, patient information leaflet.

real-world use. Variations produced in the laboratory included temperature, humidity, inhaler orientation, and inspiratory flow rate. In vitro dose delivery was also consistent upon simulation of patient use (i.e., after exposure to everyday knocks, drops, and temperature variations). The results show that dose preparation errors, which are common with DPIs, ${ }^{(13,14)}$ will be reduced when using the Spiromax DPI.

The flow rates observed in all patient groups indicate that the majority $(>98 \%)$ of patients achieved adequate flow rates $(>30 \mathrm{~L} / \mathrm{min})$ using Spiromax. Furthermore, the small number of patients with a PIFR $<30 \mathrm{~L} / \mathrm{min}$ after standard PIL training falls within expected numbers for DPIs. ${ }^{(9)}$ The results obtained with Spiromax in the laboratory are likely to provide an accurate representation of TEDs to patients in real-life conditions, regardless of their inspiratory profiles. Clinical evidence from patients using Spiromax to deliver drug therapy is now needed; one such study has recently completed and the data analyzed. ${ }^{(22,23)}$ In the clinical setting, enhanced training could be considered for patients at risk of suboptimal flow rates, such as patients with COPD. ${ }^{(8)}$

Moreover, reliability may be assured in a range of conditions designed to mimic real-world use. Treatment efficacy is unlikely to be affected by variations in inspiratory flow rate, by dropping the inhaler, or by using it where temperature or humidity is high or low. Dose consistency is also maintained when the inhaler is held at a + or $-90^{\circ}$ orientation, meaning that patients can potentially use their Spiromax inhaler while lying in bed. The $-90^{\circ}$ position (Fig. 6) corresponds to holding the device horizontal with the mouthpiece pointing downward. The results suggest little or no need for lifestyle adjustments to 'fit around the inhaler'; the Spiromax inhaler provides genuine ease of use.

There are important limitations to the interpretation and applicability of the study data. For the in vitro studies, the main limitation is the performance of studies under laboratory conditions. Although these studies were designed to evaluate the impact of normal patient behaviors on the delivered dose of DuoResp via Spiromax (such as accidently dropping the inhaler onto a hard floor), the studies cannot mimic all conceivable real-life scenarios. This is particularly the case if more than one scenario occurs simultaneously. The in vitro flow study used a vacuum pump (as recommended by the EU regulatory authorities) to generate the flow profiles used in the study. However, vacuum pumps generate a 'square' flow profile and such a profile is not exactly the same as the profiles generated during the patient flow study.

For the patient flow studies, there is the potential for bias given the open-label design of the study — participants may use an inhaler they recognize differently to one with which they are unfamiliar. Other potential limitations of the patient flow studies are completion of the study at one clinic visit, lack of information regarding clinical effect (dummy inhalers were used), and also that it is not yet established whether PIFR might differ with empty inhalers versus inhalers containing the drugs.

In conclusion, these results indicate that Spiromax delivers consistently accurate doses throughout inhaler life under controlled laboratory conditions. Consistency of overall dose is maintained when this inhaler is exposed to variations in temperature, humidity, inspiratory flow rate, and orientation during actuation/inhalation, or when it is dropped or knocked. Comparison of the flow rates achieved by patients with asthma and COPD with the in vitro dose delivery results suggest in vitro findings may also be applicable to clinical practice.

\section{Acknowledgments}

All studies were funded by Teva Pharmaceuticals. Medical writing support was provided by Lisa Moore of GeoMed, an Ashfield company, part of UDG Healthcare plc, and this support was funded by Teva Pharmaceuticals. The authors would like to thank Dr. Mary McKenry for the statistical analyses in the article.

\section{Author Disclosure Statement}

$\mathrm{HC}$ and GWC have received financial support to conduct research studies, for consultancy work, and have received honoraria for presentations from several pharmaceutical companies which market inhaled products.

GWC: A. Menarini, Almirall, AstraZeneca, Boeringher Ingelheim, Chiesi Farmaceutici, GlaxoSmithKline, Lab. Guidotti, Malesci, Mundifarma, Novartis, Teva and Valeas.

HC: Almirall, AstraZeneca, Boehringer Ingelheim, Chiesi, Cipla, GlaxoSmithKline, Innovata Biomed, Meda, MundiPharma, Orion, Teva, Trudell Medical International, 
UCB and Zentiva. HC has also received research sponsorship from grant awarding bodies (EPSRC and MRC).

JA is an employee of Teva Pharmaceuticals.

HK was an employee of Teva Pharmaceuticals during the study and manuscript development.

\section{References}

1. Laube BL, Janssens HM, de Jongh FH, Devadason SG, Dhand R, Diot P, Everard ML, Horvath I, Navalesi P, Voshaar T, and Chrystyn H: What the pulmonary specialist should know about the new inhalation therapies. Eur Respir J. 2011;37:1308-1331.

2. Giraud V, and Allaert FA: Improved asthma control with breath-actuated pressurized metered dose inhaler (pMDI): The SYSTER survey. Eur Rev Med Pharmacol Sci. 2009; 13:323-330.

3. Duerden M, and Price D: Training issues in the use of inhalers. Dis Manage Health Outcomes. 2001;9:75-87.

4. Canonica GW, Pawankar R, Baena Cagnani CE, Bousquet J, and Zuberbier T: Manifesto on adherence to treatment in respiratory allergy. Available at http://www.worldallergy.org/ UserFiles/file/GWCManifestoAdherenceChicago_fullpage_v1 .pdf. Accessed October, 2014.

5. Chrystyn H: Is inhalation rate important for a dry powder inhaler? Using the In-Check Dial to identify these rates. Respir Med. 2003;97:181-187.

6. de Boer AH, Bolhuis GK, Gjaltema D, and Hagedoorn P: Inhalation characteristics and their effects on in vitro drug delivery from dry powder inhalers: Part 3: The effect of flow increase rate (FIR) on the in vitro drug release from the Pulmicort 200 Turbuhaler. Int J Pharm. 1997;153:67-77.

7. Keating GM, and Faulds D: Airmax: A multi-dose dry powder inhaler. Drugs. 2002;62:1887-1895.

8. Al-Showair RA, Tarsin WY, Assi KH, Pearson SB, and Chrystyn H: Can all patients with COPD use the correct inhalation flow with all inhalers and does training help? Respir Med. 2007;101:2395-2401.

9. Azouz W, Chetcuti P, Hosker HS, Saralaya D, Stephenson J, Chrystyn H: The inhalation characteristics of patients when they use different dry powder inhalers. J Aerosol Med Pulm Drug Deliv. 2015;28:35-42.

10. Kanabuchi K, Kondo T, Tanigaki T, Tajiri S, Hayama N, Takahari Y, and Iwao K: Minimal inspiratory flow from dry powder inhalers according to a biphasic model of pressure vs. flow relationship. Tokai J Exp Clin Med. 2011;36:1-4.

11. Thomas M, and Williams AE: Are outcomes the same with all dry powder inhalers? Int J Clin Pract Suppl. 2005;149:33-35.

12. Pauwels R, Newman S, and Borgstrom L: Airway deposition and the airway effects of antiasthma drugs delivered from metered-dose inhalers. Eur Respir J. 1997;10:2127-2138.

13. Melani AS, Bonavia M, Cilenti V, Cinti C, Lodi M, Martucci P, Serra M, Scichilone N, Sestini P, Aliani M, Neri M, and Gruppo Educazionale Associazione Italiana Pneumologi Ospedalieri: Inhaler mishandling remains common in real life and is associated with reduced disease control. Respir Med. 2011;105:930-938.

14. Molimard M, Raherison C, Lignot S, Depont F, Abouelfath A, and Moore N: Assessment of handling of inhaler devices in real life: An observational study in 3811 patients in primary care. J Aerosol Med. 2003;16:249-254.
15. European Medicines Agency (EMA) approval (DuoResp Spiromax). Available at http://www.ema.europa.eu/docs/ en_GB/document_library/EPAR_-_Product_Information/ human/002348/WC500167182.pdf. Accessed October, 2014.

16. European Medicines Agency: Guideline on the pharmaceutical quality of inhalation and nasal products. EMEA/CHMP/ QWP/49313/2005 Corr. 2006. Available at http://www.ema .europa.eu/docs/en_GB/document_library/Scientific_guideline/ 2009/09/WC500003568.pdf. Accessed October, 2014.

17. European Medicines Agency: Requirements for clinical documentation for orally inhaled products (OIP) including the requirements for demonstration of therapeutic equivalence between two inhaled products for use in the treatment of Asthma and Chronic Obstructive Pulmonary Disease (COPD) in adults and for use in the treatment of asthma in children and adolescents. CPMP/EWP/4151/00 Rev. 1 2009. Available at http://www.ema.europa.eu/docs/en_GB/ document_library/Scientific_guideline/2009/09/WC500003504 .pdf. Accessed December 19, 2014.

18. European Pharmacopoeia: Preparations for Inhalation (01/ 2012:671). 8th edition. Council of Europe, 2013.

19. Clark AR, and Hollingworth AM: The relationship between powder inhaler resistance and peak inspiratory conditions in healthy volunteers-implications for in vitro testing. J Aerosol Med. 1993;6:99-110.

20. Broeders ME, Molema J, Vermue NA, and Folgering HT: Peak inspiratory flow rate and slope of the inhalation profiles in dry powder inhalers. Eur Respir J. 2001;18:780-783.

21. Azouz W, Chetcuti P, Hosker HS, Saralaya D, and Chrystyn H: Inhalation characteristics of asthma patients, COPD patients and healthy volunteers with the Spiromax ${ }^{\circledR}$ and Turbuhaler ${ }^{\circledR}$ devices: A randomised, cross-over study. BMC Pulm Med. 2015;15:47.

22. Gopalan G, Virchow JC, and Shu Y: A trial to establish the efficacy and safety of budesonide/formoterol 160/4.5 mcg from a novel dry-powder inhaler (DPI) versus budesonide/ formoterol 200/6 mcg from a DPI in adult and adolescent patients with persistent asthma. Allergy. 2014;69:291-292.

23. Virchow JC, Gopalan G, Rodriguez-Roisin R, and Shu Y: Efficacy and safety of budesonide-formoterol (BF) Spiromax ${ }^{\circledR}$ in adults and adolescents with asthma: Randomised comparison with BF Turbuhaler ${ }^{\circledR}$. Thorax. 2014;69:A176.

Received on March 11, 2015 in final form, August 5, 2015

Reviewed by: Heidi Mansour Michael Hindle

Address correspondence to: Henry Chrystyn, PhD Inhalation Consultancy Ltd Tarn House 77 High Street Yeadon

Leeds LS19 7SP United Kingdom

Email: h.chrystyn@gmail.com

\footnotetext{
${ }^{\dagger}$ Formerly Division of Pharmacy, School of Applied Sciences, University of Huddersfield, Huddersfield.
} 